\title{
Vitamin D deficiency and its effects on patients with multiple myeloma
}

\begin{abstract}
Objective: It was aimed to evaluate Vitamin D deficiency and its relationship with chemotherapies, autologous stem cell transplantation, bone density, and fractures in patients with MM in this study.
\end{abstract}

Patients and method: In this retrospective study, patients who were diagnosed with MM and followed up at the hematology department between June 2014 and December 2014 were evaluated in terms of vit-D level in the blood, retrospectively.

Results: Of 31patients with MM, 19 cases were male. The median age was 63 (Range:49-90years). The mean vit-D level was $11.9 \pm 7.6 \mathrm{ng} / \mathrm{ml}$, and was low in 20 of 33 cases $(93 \%)$. The vit D level was significantly lower in cases whom a greater number of chemotherapy cycles was administered $(\mathrm{p}=0.033)$. There was no statistically significant relationship between blood vit D level and bone fracture development $(\mathrm{p}=0.55)$, DEXA results $(\mathrm{p}=0.703)$, International Staging System (ISS) stage, and whether ABMT had been performed or not $(\mathrm{p}=0.752)$.

Conclusion: Osteoporosis, osteonecrosis and fracture are more observed in MM patients in relation with low vit $\mathrm{D}$ level in the blood that is more common in advanced age and corticosteroid use.

Keywords: multiple myeloma, vitamin D, bisphosphonates, bone lesions
Volume 5 Issue 2 - 2017

\author{
Osman Yokuș,' Hilmi Dogu M,' Aydinli F,' \\ Eren R,' Altindal S,' Habip Gedik' \\ 'Department of Hematology, Ministry of Health İstanbul Training \\ and Research Hospital, Turkey \\ ${ }^{2}$ Department of Infectious Diseases and Clinical Microbiology, \\ Ministry of Health Bakırköy Sadi Konuk Training and Research \\ Hospital,Turkey
}

\begin{abstract}
Correspondence: Habip Gedik, Department of Infectious Diseases and Clinical Microbiology, Ministry of Health Bakırköy Sadi Konuk Training and Research Hospital, İstanbul, Turkey, Fax +90212221 78 00, Tel +902123145555,

Email habipgedik@yahoo.com
\end{abstract}

Received: July 21, 2017 | Published: August 30, 2017
Abbreviations: ISS, international staging system; MM, multiple myeloma; DXA, dual energy X-ray absorptiometry; ASCT, autologous stem cell transplantation; PTH, parathormone; BDT, bone densitometry; IMWG, international myeloma working group; BPs, bisphosphonates; ZOL, zoledronic acid; PAM, pamidronate; ABMT, autologous bone marrow transplantation

\section{Introduction}

Vitamin D [1.25-dihydroxyvitamin D;1.25(OH) 2D3;vit D] has multiple functions in cellular proliferation, differentiation, angiogenesis inhibition and apoptosis stimulation in addition to main role in skeletal system metabolism. The lytic lesions, hypercalcemia, compression fractures, and the related pains are commonly seen related to bone resorption in multiple myeloma (MM). ${ }^{1}$ The main source of vit D is natural sunlight, and the main reason of vit D deficiency is inadequate exposure to sunlight. Obesity, insufficient dietary intake, malabsorption, some drugs (such as anticonvulsant drugs and disorders that increase the metabolism of the vitamin, such as lymphoma and hyperthyroidism that causes also a tendency for vit $\mathrm{D}$ deficiency. ${ }^{2,3}$ The development and poor prognosis of various solid cancers, such as prostate and breast cancers have also been reported to be associated with lower serum vit D level-1. Similarly, some articles have reported a relationship between $\mathrm{MM}$ and vit D deficiency, a poor prognosis in MM cases with lower vit D level, and increased MM incidence in places with less sunlight. ${ }^{4,5}$ Some other studies have demonstrated a relationship between vit D deficiency and skeletal system complications developing in patients diagnosed with MM. ${ }^{6}$ Administration of 800 units of vit D3 (cholecalciferol) together with $100 \mathrm{mg}$ of calcium ion under close monitoring of the serum calcium is recommended for subjects with vit D deficiency or inadequacy, if there is no hypercalcemia.
The vitamin D deficiency rate has been shown to increase further in the advanced stages of MM. A study has investigated the serum vit $\mathrm{D}$ level in the first 15days of newly diagnosed MM patients, and evaluated its relationship with disease stage. Patients with low vit D levels were reported to have a more advanced stage of MM, higher CRP and creatinine levels, lower albumin levels in addition to more advanced International Staging System (ISS) stages. They reported that the amount of vit D deficiency increased in parallel with the higher ISS stages (vit D deficiency rate of $16 \%$ in Stage I, $20 \%$ in Stage II, and $37 \%$ in stage III). ${ }^{5}$ Our primary aim in this study was to determine the vit $\mathrm{D}$ deficiency and its relationship with the stage of $\mathrm{MM}$ as we had not come across any previous publication. Our secondary aims were to determine the relationship between vit $\mathrm{D}$ deficiency and ISS stages, the mineral density loss, bone fractures and autologous stem cell transplantation, and finally to determine whether a relationship was present between the vit $\mathrm{D}$ level and the number of different chemotherapy regimens used an indirect indicator of the disease stage.

\section{Patients and methods}

In this retrospective study, patients who were diagnosed with MM and followed up as an outpatient at the hematology department between the $6^{\text {th }}$ and $12^{\text {th }}$ month of 2014 were screened in terms of vit D level in the blood. After informed consent was obtained from the patients, the patient information and test results were retrospectively obtained from the patient charts and computer records. We analyzed the hemogram, biochemical tests, serum immunoglobulins, serum/ urine immunofixation electrophoresis and many other tests and also the results of the bone marrow aspiration and biopsy obtained during the diagnosis and treatment processes together with the informative material necessary for the study. The vit D level and the reports of 
imaging methods such as x-ray or CT/MR up to the period of bone densitometry (lumbar/femoral) records were evaluated whether there was any fracture as the most severe skeletal system morbidity until that time. We used the "2011 Guide for the evaluation and treatment of vitamin D deficiency in clinical practice" of the International Endocrine and the reference ranges in the current publications as our reference for the serum vitamin D levels in our study. ${ }^{5}$ The guide states that a vitamin $\mathrm{D}$ value of less than $20 \mathrm{ng} / \mathrm{ml}(50 \mathrm{nmol} / \mathrm{L})$ is vit $\mathrm{D}$ deficiency, $21-29 \mathrm{ng} / \mathrm{ml}(52.5-72.5 \mathrm{nmol} / \mathrm{L})$ is the Vit $\mathrm{D}$ inadequacy and $30 \mathrm{ng} / \mathrm{ml}$ and over is adequate (normal). We excluded patients who had a disorder or medication use that could influence the vit D level (chronic kidney failure, anticonvulsant drugs, and regular vitamin D treatment)

We used ISS as the prognostic score at the time when MM patients underwent vit $\mathrm{D}$ and bone densitometry tests. In this score system, if albumin over $3.5 \mathrm{mg} / \mathrm{dl}$ and $\beta_{2}$ microglobulin under $3.5 \mathrm{mg} / \mathrm{dl}$ is stage I, albumin under $3.5 \mathrm{mg} / \mathrm{dl}$ and $\beta_{2}$ microglobulin over $3.5 \mathrm{mg} / \mathrm{dl}$ is stage II and $\beta_{2}$ microglobulin over $5.5 \mathrm{mg} / \mathrm{dl}$ is stage III. The ISS score at the time of the tests, the treatments that patients had received, history of autologous stem cell transplant, and the remission status of the patient was recorded. The bone mineral density measurements of our patients were performed by the Dual Energy X-Ray absorptiometry (DXA) method as a gold standard. There is an inverse relationship between BMD and fracture risk. The $\mathrm{Z}$ score is interpreted according to the $\mathrm{T}$ score in this technique. As the $\mathrm{T}$ score is more valuable and more commonly used, we therefore interpreted the values by $\mathrm{T}$ score. Each standard deviation in this measurement is known to increase the fracture risk three times. We interpreted the $\mathrm{T}$ score according to the WHO recommendations as follows: T-score $>1$ normal, $-1>$ T-score $>-2.5$ osteopenia, i.e. the risk group, $\mathrm{T}$ score $<-2.5$ osteoporosis, i.e. the high risk group. ${ }^{8}$ We similarly used the age-adjusted densitometry results of the femur and lumbar region for our bone densitometry analysis. If the $\mathrm{T}$ score is $\geq-2.5$, it was defined as osteoporosis, from -1.5 to -2.5 defined as osteopenia, and $<-1.5$ defined as normal bone density in our study. We also evaluated whether vit D deficiency was correlated with an increased number of chemotherapy session. We classified the patients as a group I including patients who had received 0 to 2 chemotherapy cycles, and group II including those who had received 3 to 5 chemotherapy cycles.

\section{Statistical methods}

The SPSS 15.0 Windows software was used for the statistical analysis of the results. Descriptive statistics were presented as numbers and percentages for categorical variables and mean, standard deviation, minimum and maximum for numerical variables. For the comparison of two independent groups, Student's t-test was used if normal distribution was present; otherwise the Mann-Whitney U test was used. Comparison of more than two groups was analyzed by the Kruskal-Wallis test if the normal distribution condition was not met. Subgroup analyses were performed with the Mann-Whitney U test for nonparametric variables applying the bonferroni correction. The inter-group rates of categorical variables were tested with ChiSquare analysis. The relationship of ordinal variables with numerical variables was analyzed with Spearman's correlation analysis. The alpha significance level was accepted at $\mathrm{p}<0.05$.

\section{Results}

We evaluated a total of $31 \mathrm{MM}$ patients with a mean age of $63.7 \pm 10.5(49-90)$ to the study and consisting of 19 males (61.3\%), retrospectively. Myeloma-related clinical findings (CRAB) were present, and chemotherapy had been administered to almost all patients at the time of diagnosis. Only one case was followed-up without treatment with a diagnosis of smoldering myeloma. Two of these 31 cases under follow-up have died due to disease-related complications in the last three months. The mean vitamin D level of all patients was $11.9 \pm 7.6 \mathrm{ng} / \mathrm{ml}$. The vit D level was normal in one case $(3.2 \%)$, inadequate in one case $(3.2 \%)$, and deficient in other cases $(29 / 31,93.5 \%)$. There was no statistically significant difference between the vit $\mathrm{D}$ levels and general features of the gender groups (Table 1). Vit D values were $19.7 \mathrm{ng} / \mathrm{ml}$ in five patients with stage-I, $9.7 \mathrm{ng} / \mathrm{ml}$ in 11 cases with stage-II, and $10.9 \mathrm{ng} / \mathrm{ml}$ in 15 cases with stage-III. There was no statistically significant difference between the vit D levels and stages of the patients (Table 2). The mean vit D level statistically significantly lower in group I $15.6 \pm 9.4 \mathrm{ng} / \mathrm{ml}$ than $9.1 \pm 4.8 \mathrm{ng} / \mathrm{ml}$ in group II ( $\mathrm{p}=0.033$; Table 3$)$. There were recorded one or more fractures in $12(38 \%)$ patients. The vit D level was no statistically significant different in those with a fracture $(9.9 \pm 4.6 \mathrm{ng} /$ $\mathrm{ml})$ and in those without fracture $(13.2 \pm 8.9 \mathrm{ng} / \mathrm{ml} ; \mathrm{p}=0.556$; Table 4). The fracture was recorded in $17(58 \%)$ of the cases with severe vit $\mathrm{D}$ deficiency. The bone density measurement (DEXA), which could be performed in 28 cases, revealed osteoporosis in 16cases $(57 \%)$, osteopenia in six cases $(21 \%)$, and normal finding in the rest. There was no statistically significant relationship between DEXA results and vit $\mathrm{D}$ levels ( $\mathrm{p}=0.703$; Table 5 ). The vit $\mathrm{D}$ levels of patients who had undergone autologous stem cell transplantation (ASCT) were no statistically significant difference compared to cases that had not undergone to ASCT ( $\mathrm{p}=0.752$; Table 6 ).

Table I General features and results of Multiple Myeloma cases where the vit D level had been determined

\begin{tabular}{|c|c|c|c|c|c|}
\hline & & $\begin{array}{l}\text { Total } \\
\mathbf{N}(\%)\end{array}$ & $\begin{array}{l}\text { Female } \\
\mathbf{N}(\%)\end{array}$ & $\begin{array}{l}\text { Male } \\
\text { N(\%) }\end{array}$ & $\mathbf{P}$ \\
\hline \multicolumn{2}{|l|}{ Age* } & $63(49-90)$ & $65(53-90)$ & $6 I(49-8 I)$ & 0.168 \\
\hline \multirow{3}{*}{ MM type } & Smoldering & $\mathrm{I}(3.2)$ & $\mathrm{I}(8.3)$ & $0(0.0)$ & \multirow{3}{*}{0.387} \\
\hline & MM & $30(96.8)$ & II(9I.7) & $19(100)$ & \\
\hline & 1 & $5(16.1)$ & $2(16.7)$ & $3(15.8)$ & \\
\hline \multirow[t]{2}{*}{ Stage } & 2 & II(35.5) & $5(41.7)$ & $6(31.6)$ & \multirow[t]{2}{*}{0.882} \\
\hline & 3 & $15(48.4)$ & $5(41.7)$ & $10(52.6)$ & \\
\hline \multicolumn{2}{|c|}{ Vitamin D Level*(ng/ml) } & $\mid I .9 \pm 7.6(4.5-4 \mid)$ & 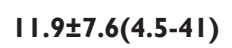 & $10.3 \pm 6.8(4.6-26)$ & \\
\hline & Normal & $\mathrm{I}(3.2)$ & $0(0.0)$ & $I(5.3)$ & \\
\hline \multirow[t]{2}{*}{ Vitamin D } & Inadequate & $\mathrm{I}(3.2)$ & $\mathrm{I}(8.3)$ & $0(0.0)$ & 0.64 \\
\hline & Deficient & $29(93.5)$ & II(91.7) & |8(94.7) & \\
\hline
\end{tabular}


Table Continued....

\begin{tabular}{|c|c|c|c|c|c|}
\hline & & $\begin{array}{l}\text { Total } \\
\text { N(\%) }\end{array}$ & $\begin{array}{l}\text { Female } \\
\text { N(\%) }\end{array}$ & $\begin{array}{l}\text { Male } \\
\text { N(\%) }\end{array}$ & $\mathbf{P}$ \\
\hline \multirow{3}{*}{ DEXA result } & Normal & $6(21.4)$ & $4(36.4)$ & $2(11.8)$ & \multirow{3}{*}{0.25} \\
\hline & Osteopenic & $6(21.4)$ & $I(9.1)$ & $5(29.4)$ & \\
\hline & Osteoporotic & $16(57.1)$ & $6(54.5)$ & $10(58.8)$ & \\
\hline \multirow[t]{2}{*}{ Fracture presence } & & $12(38.7)$ & $5(4 I .7)$ & $7(36.8)$ & I \\
\hline & OI-Feb & $13(43.3)$ & $4(33.3)$ & $9(50.0)$ & \multirow{3}{*}{0.452} \\
\hline \multirow[t]{2}{*}{ Number of $\mathrm{CT}^{* *}$} & 03-May & $16(53.3)$ & $7(58.3)$ & $9(50.0)$ & \\
\hline & None & $\mathrm{I}(3.3)$ & $\mathrm{I}(8.3)$ & $0(0.0)$ & \\
\hline \multirow{2}{*}{ Transplant(ABMT) } & No & $16(51.6)$ & $8(66.7)$ & $8(42.1)$ & \multirow{2}{*}{0.183} \\
\hline & Yes & I5(48.4) & $4(33.3)$ & II(57.9) & \\
\hline \multirow{2}{*}{ Recurrence } & Recurrence & $14(45.2)$ & $7(58.3)$ & $7(36.8)$ & \multirow{2}{*}{0.242} \\
\hline & Remission & I7(54.8) & $5(4 I .7)$ & $12(63.2)$ & \\
\hline
\end{tabular}

*Median(min-max)

** CT, chemotherapy

Table 2 Vitamin D level and international staging system (ISS)

\begin{tabular}{lcccccccc}
\hline \multicolumn{1}{l}{ International staging system(ISS) } & & & & & \\
\hline & I & & $\mathbf{2}$ & & 3 & & \\
& & n & $\%$ & $\mathbf{n}$ & $\%$ & $\mathbf{n}$ & $\%$ & P \\
Vit D & Normal & I & 20 & 0 & 0 & 0 & 0 & \\
& Inadequacy & 0 & 0 & 0 & 0 & I & 6.7 & 0.449 \\
& Deficiency & 4 & 80 & II & I00 & I4 & 93.3 &
\end{tabular}

Vitamin D Level

\begin{tabular}{llllll} 
& & & $\begin{array}{l}\text { Mean } \pm \\
\text { SD }\end{array}$ & Minimum & Maximum \\
& 1 & $19.7 \pm 12.2$ & 10.7 & $4 \mid$ & \\
STAGE & 2 & $9.7 \pm 5.1$ & 4.5 & 18 & 0.107 \\
& 3 & $10.9 \pm 6.1$ & 4.6 & 26 & \\
\hline
\end{tabular}

Table 3 Vitamin D Level and chemotherapy status of patients

\begin{tabular}{lllll}
\hline Vitamin D level & & & & \\
\hline Number of CT* & Mean士 SD & Minimum & Maximum & p \\
\hline OI-Feb & $15.6 \pm 9.4$ & 4,8 & 41 & \\
03-May & $9.1 \pm 4.8$ & 4.5 & 17.5 & 0.033 \\
None & 13.5 & & & \\
\hline
\end{tabular}

*CT Chemotherapy

Table 4 Vitamin $D$ level and fracture status of patients

\begin{tabular}{lcccc}
\hline \multicolumn{2}{l}{ Vitamin D level } & & & \\
\hline Fracture & Mean \pm SD & Minimum & Maximum & P \\
\hline Present & $13.2 \pm 8.9$ & 4.5 & $4 \mathrm{l}$ & \\
Absent & $9.9 \pm 4.6$ & 4.8 & 16.2 & 0.556 \\
\hline
\end{tabular}

Table 5 Vitamin D level and dexa status of patients

\begin{tabular}{lllll}
\hline \multicolumn{1}{l}{ Vitamin D level } & & & & \\
\hline DEXA & Mean士SD & Minimum & Maximum & P \\
\hline Normal & $10.2 \pm 5.4$ & 4.5 & 18 & \\
Osteopenic & $16.1 \pm 13.5$ & 4.8 & 41 & 0.703 \\
Osteoporotic & $9.6 \pm 4.1$ & 4.6 & 16.2 &
\end{tabular}

Table 6 Vitamin D level and transplant/ disease status of patients

\begin{tabular}{lllll}
\hline Vitamin D level & & & & \\
\hline $\begin{array}{l}\text { Transplant } \\
\text { status(ABMT) }\end{array}$ & Mean \pm SD & Minimum & Maximum & P \\
\hline No & $11.4 \pm 6.0$ & 4.8 & 26 & 0.752 \\
Yes & $12.4 \pm 9.2$ & 4.5 & $4 \mid$ & \\
Disease Status & & & & \\
Recurrence & $10.1 \pm 6.4$ & 4.6 & 26 & 0.275 \\
Remission & $13.4 \pm 8.4$ & 4.5 & $4 \mid$ & \\
\hline
\end{tabular}

\section{Discussion}

Vitamin D plays a key role in the development of the skeletal system in addition to calcium and phosphorus homeostasis. Vitamin D deficiency leads to rickets in children and osteomalacia in adults. ${ }^{9}$ Osteoporosis is a skeletal system disease where the bone mass decreases and there are changes in the microstructure causing a tendency to fracture. The reason is usually aging, the menopause and steroid use. ${ }^{10}$ Osteomalacia is usually together with osteoporosis in later years. Vitamin D plays a role in the mineralization of the bone organic matrix, so its deficiency leads to bone resorption and osteoporosis due to parathormone (PTH) stimulation. Aging also decreases the bone density, and increases the fracture risk. The reported vitamin D deficiency incidence is $30 \%$ of the population, and increases further with aging. In MM patients, the intensive and long-term steroid use as a part of treatment causes decreased bone 
density, osteoporosis and skeletal system morbidity. ${ }^{11}$ Patients, who have an osteoporosis-related chronic disease, history of long-term corticosteroids (more than $7.5 \mathrm{mg}$ per day for 6 months), and over the age of 50years, should be investigated for osteoporosis with imaging tests. The measurements of vit D level and bone densitometry (BDT) are recommended in patients with osteopenia and/or a vertebral deformity. There is an inverse relationship between bone densitometry results and the fracture risk. Every decrease in the bone density has been reported to increase the fracture incidence 2-3 times. ${ }^{12,13}$ Most of our patients were over 50years old, and we used to evaluate the mean value of $\mathrm{T}$ scores for the femur and lumbar vertebrae, as the WHO recommended for patients older than 50years. ${ }^{14}$

The vit $\mathrm{D}$ values of the cases were lower when compared with the literature. ${ }^{15}$ Vit D deficiency rates were reported of $16-37 \%$ in MM patients, and increasing correlated with increasing ISS stages. ${ }^{5}$ The pre-Autologous Bone Marrow Transplantation (ABMT) vit D levels of MM patients were reported to be low $(25-\mathrm{OH}-\mathrm{D}<20 \mathrm{ng} / \mathrm{ml})$ in $68 \%$ of the cases. ${ }^{15}$ The vit D levels of our cases in ISS stages II and III that is related to poor prognosis were lower consistent with the reported levels. However, the lack of statistical significance is more likely to be related to fewer patients than other reported studies, and also the dynamic nature of ISS staging that decreases to stage I with chemotherapy or increases to stage III with relapse at the time of the vit $\mathrm{D}$ measurement. Low levels of vit $\mathrm{D}$ have been reported in $\mathrm{MM}$ patients with hypercalcemia just like those with normo/hypocalcemia. Lawson et al. have evaluated serum vit D levels in $25 \mathrm{MM}$ patients older than 50years, and found that the vit D level was frequently low in both hypercalcemic and hypocalcemic cases, i.e. it was independent of the blood calcium level. ${ }^{16}$

It has also been reported that vit $\mathrm{D}$ deficiency could be responsible for the frequent musculoskeletal pains in MM patients and that these symptoms may be ignored as they are thought to be due to the patient's disorder. A 63-year-old MM patient receiving bortezomib suffered frequent musculoskeletal pains and falls, and the tests revealed osteomalacia with a very low blood vit $\mathrm{D}$ level at $20 \mathrm{nmol} / \mathrm{L}$. The symptoms recovered markedly within 4 months with vit $\mathrm{D}$ replacement. ${ }^{10}$ This indicates that vit $\mathrm{D}$ plays a major role in the musculoskeletal system pains in MM patients, and these symptoms could resolve with vit D replacement. Vit D deficiency should therefore be investigated in patients with such complaints. ${ }^{17}$ The fact that most of our MM patients were over the age of 50years (mean age 60years) and the further decrease in vit D levels with age could increase MM-related bone complications. Such investigations are therefore all the more important in decreasing the bone-related complications that can develop in MM patients of advanced age. The bones and the kidneys are the two main target organs in MM in terms of serious morbidity. The main pathophysiological reason of the bone morbidity in MM is the increased osteoclastic activity and the osteoporosis that is seen concurrently with complications, such as bone fractures. Bisphosphonate group drugs are therefore administered for approximately two years as preventive treatment.

The 2013 recommendations of the International Myeloma Working Group (IMWG) for the treatment of bone disorders related to $\mathrm{MM}$ include the use of bisphosphonates (BPs), regardless of whether osteolytic lesions are present in conventional X-rays, as part of the treatment in all MM patients at the time of diagnosis. Among the bisphosphonates, intravenous (IV) zoledronic acid (ZOL) or pamidronate (PAM) are primarily suggested as they have been shown to have an anti-myeloma effect, while oral clodronate is recommended as a second step, if these cannot be used due to nephrotoxicity or other reasons. These drugs are administered once every 4weeks as long as the disorder is active. They can be stopped after approximately 2 years of use, if there is full response or very good partial response. Readministration of those drugs is recommended, if there is recurrence. ${ }^{18}$ The vit $\mathrm{D}$, calcium, phosphate, magnesium and albumin levels and the renal functions should be evaluated before bisphosphonate use in malignant disorders. ${ }^{19}$ It is especially important to choose the bisphosphonate dose and type properly due to the nephrotoxicity risk. All our patients received bisphosphonate treatment, with 26 receiving 'zoledronic acid' and 5 'Clodronate hydrochloride'. Bisphosphonate use may cause an increased incidence of symptomatic hypocalcemia and related symptoms, especially when vit D deficiency is present. Various articles suggest checking the vit D level in patients with hypocalcemia due to bisphosphonates, and replacing it if it is necessary. ${ }^{20}$ We therefore administered combination of oral calcium/ vit $\mathrm{D}$ preparations for our patients found to have vit $\mathrm{D}$ deficiency and routinely checked the serum calcium levels especially before monthly intravenous bisphosphonate administration. Hypocalcemia was found in three of our patients, and the vit D levels of these cases were very low $(<10 \mathrm{ng} / \mathrm{ml})$. The clinical and laboratory values recovered following calcium/vit D replacement. Studies have also shown that administration of $800 \mathrm{IU}(20 \mathrm{mcgr})$ vit D and $1200 \mathrm{mg}$ calcium daily to patients in covered institutions decreases the risk of falls and fractures. $^{21}$

Tooth extraction while using nitrogen-containing bisphosphonates increases the risk of jaw osteonecrosis A study has reported a jaw osteonecrosis development risk of $66 \%$ in the rat animal model with vit $\mathrm{D}$ deficiency while receiving zoledronic acid, $14 \%$ in those with a normal vit $\mathrm{D}$ level and receiving zoledronic acid treatment, and $0 \%$ in the control group with vit D deficiency. This study indicates that vit $\mathrm{D}$ may play a role in preventing osteonecrosis development in MM cases. ${ }^{22}$ We also found in this study that vit D deficiency was more frequent and more marked in patients who had received a large number of (different) chemotherapy regimes, an indirect indicator of a refractory disorder. The vit $\mathrm{D}$ deficiency is more marked in the later stages of the disorder. The medication, less exposure to sunlight because of the disorder, a vit $\mathrm{D}$ poor diet, or the inability to ingest diet with adequate vit $\mathrm{D}$ could be reasons.

ABMT had been performed in some $(48 \%)$ of the patients where vit $\mathrm{D}$ had been measured and we found no difference when the levels were compared with patients who had not undergone ABMT $(\mathrm{p}=0.752)$. Another article has reported checking the serum vit D levels and biochemical parameters related to bone metabolism (serum calcium,25-OH-D, PTH 1-84, bone alkaline phosphatase, serum C-terminal cross-linking telopeptide and lumbar vertebra bone mineral density) before and 12 months after transplantation in 39 MM patients who had undergone autologous stem cell transplantation. The vit D level was $<20 \mathrm{ng} / \mathrm{ml}$ in $66 \%$ of the cases indicating vit $\mathrm{D}$ deficiency while the vit $\mathrm{D}$ deficiency rate 12 months after transplantation was $58 \%$ and there was no difference regarding bone production parameters. ${ }^{15}$ Treating the present osteoporosis in patients with fractures is quite important to prevent potential future fractures. It has been reported that patients without $\mathrm{MM}$ who have suffered a bone fracture due to osteoporosis have a secondary factor causing bone loss in $80 \%$ of the cases and that the most common ones are aging and vit D deficiency (61\%). ${ }^{23}$ Similarly, our patients were aged and almost all had vit D deficiency with bone mass loss in $78 \%$ (osteoporosis in 57\%, osteopenia in $21.4 \%$ ) and the mean vit D level in the cases with osteoporosis was markedly low at $9.6 \mathrm{ng} / \mathrm{ml}$. These 
indicate that vit $\mathrm{D}$ deficiency and bone mineral density should be investigated in the elderly and at risk patients and suitable treatment recommended according to the results in addition to bisphophonate treatment to prevent the bone complications and recurrent fractures in MM.

Osteoporosis-increasing factors, such as vit D deficiency, should be investigated and treated to prevent recurrence in patients with a fracture. Bisphosphonate treatment is an effective measure to prevent recurrence. ${ }^{24}$ It has recently been reported that the proteasome inhibitor bortezomib stimulates osteoblastic differentiation and modifies vit $\mathrm{D}$ signals through the blockage of proteosomal degradation via the vit D receptor although the mechanism is not fully known. Experimental studies have shown disturbed differentiation of osteoblastic progenitors related to vit $\mathrm{D}$ in the presence of myeloma cells, and an increase has been found in the moderate osteoblastic differentiationrelated molecules with bortezomib treatment. It was noticed that this became more marked when vit $\mathrm{D}$ was added. This study has stated that adding vit $\mathrm{D}$ to the treatment is essential for optimal bone formation to occur in patients receiving bortezomib. ${ }^{25}$

\section{Conclusion}

Decreased concentration of Vitamin D (1.25(OH) 2D3) can affect tumor metabolism in addition to the skeletal system. A low vit D level has been found in $20-60 \%$ of the MM patients in the literature and $96.7 \%$ in our study indicating that vit $\mathrm{D}$ deficiency should be investigated and replaced by monitoring the blood calcium level to decrease the bone complications of MM, to produce a beneficial effect on tumor metabolism, and to increase the potential osteoblastic activities of chemotherapeutics, such as bortezomib, especially in patients at an advanced age and with a high risk of bone fracture as it is one of the reversible risk factors. Prospective studies with a larger number of patients and better design are needed to clarify which patients require a vit $\mathrm{D}$ level and BMD evaluation and treatment as it will be possible to elucidate the relationship between the blood vit $\mathrm{D}$ level and the prognosis and complications of the disorder in this way.

\section{Acknowledgements}

None.

\section{Conflict of interest}

The authors of this paper have no conflicts of interest, including specific financial interests, relationships, and/or affiliations relevant to the subject matter or materials included.

\section{References}

1. Gupta D, Vashi PG, Trukova K, et al. Prevalence of serum vitamin D deficiency and insufficiency in cancer: Review of the epidemiological literature. Exp Ther Med. 2011;2(2):181-193.

2. Holick MF. Vitamin D deficiency. N Engl J Med. 2007;357(3):266-281.

3. Holick MF, Binkley NC, Bischoff-Ferrari HA, et al. Evaluation, treatment, and prevention of Vitamin D deficiency: An endocrine society clinical practice guideline. J Clin Endocrinol Metab. 2011;96(7):19111930 .

4. Mohr SB, Gorham ED, Garland CF, et al. Are low ultraviolet B and vitamin D associated with higher incidence of multiple myeloma? $J$ Steroid Biochem Mol Biol. 2015;148:245-252.

5. Ng AC, Kumar SK, Rajkumar SV, et al. Impact of vitamin D deficiency on the clinical presentation and prognosis of patients with newly diagnosed multiple myeloma. Am J Hematol. 2009;84(7):397-400.
6. Diamond T, Golombick T, Manoharan A. Vitamin D status may effect the skeletal complications of multiple myeloma. Am J Hematol. 2010;85(4):302-303

7. Dietary Reference Intakes for Calcium and Vitamin D. In: Ross AC, et al. editors. The national academies collection: reports funded by National Institutes of Health. Washington, USA: National Academies Press; 2011.

8. World Health Organization. Assessment of fracture risk and its application to screening for postmenopausal osteoporosis. WHO Technical Report Series 843, Geneva, Switzerland: WHO; 1994.

9. Edlich R, Mason SS, Chase ME, et al. Scientific documentation of the relationship of vitamin D deficiency and the development of cancer. $J$ Environ Pathol Toxicol Oncol. 2009;28(2):133-141.

10. Emkey GR, Epstein S. Secondary osteoporosis: Pathophysiology \& diagnosis. Best Pract Res Clin Endocrinol Metab. 2014;28(6):911-935.

11. Simon J, Leboff M, Wright J, et al. Fractures in the elderly and vitamin D. J Nutr Health Aging. 2012;6(6):406-412.

12. Akpolat V. Osteoporoz Tanısında Kullanılan Kemik Mineral Yoğunluğu Ölçüm Yöntemleri (Bone Mineral Density Measurement Methods That Are Used At Diagnosis of Osteoporosis). DicleTipDergisi. 2012;35(3):216-220.

13. Diamond T, Levy S, Day P, et al. Biochemical, histomorphometric and densitometryc changes in patients with multiple myeloma: effects of glucocorticoid therapy and disease activity. Br J Haematol. 1997;97(3):641-648

14. Choe PG, Choi HJ, Kim NH, et al. High prevalence of low bone mass and associated factors in Korean HIV-positive male patients undergoing antiretroviral therapy. J Int AIDS Soc. 2014;17:18773.

15. Laroche M, Lemaire O, Attal M. Vitamin D deficiency does not alter biochemical markers of bone metabolism before or after autograft in patients with multiple myeloma. Eur J Haematol. 2010;85(1):65-67.

16. Lawson-Matthew P, Clayton J, Guilland-Cumming D, et al. Vitamin D metabolism in myeloma. Br J Haematol. 1989;73(1):57-60.

17. Clement Z, Ashford M, Sivakumaran S. Vitamin D deficiency in a man with multiple myeloma. N Am J Med Sci. 2011;3(10):469-471.

18. Terpos E, Morgan G, Dimopoulos MA, et al. International Myeloma Working Group recommendations for the treatment of multiple myeloma related bone disease. J Clin Oncol. 2013;31(18):2347-2357.

19. Broadbent A, Glare P, Crawford B. Bisphosphonate induced hypocalcemia associated with vitamin D deficiency in a patient with advanced cancer. Am J Hosp Palliat Care. 2005;22(5):382-384.

20. Henley D, Kaye J, Walsh J, et al. Symptomatic hypocalcaemia and renal impairment associated with bisphosphonate treatment in patients with multiple myeloma. Intern Med J. 2005;35(12):726-728.

21. Mosekilde L. Vitamin D and the elderly. Clin Endocrinol (Oxf). 2005;62(3):265-281.

22. Hokugo A, Christensen R, Chung EM, et al. Increased prevalence of bisphosphonate related osteonecrosis of the ja with vitamin D deficiency in rats. J Bone Miner Res. 2010;25(6):1337-1349.

23. Dixon T, Mitchell P, Beringer T, et al. An overview of the prevalence of 25-hydroxy-vitamin $\mathrm{D}$ in adequacy amongst elderly patients with or without fragility fracture in the United Kingdom. Current Medical Research and Opinion. 2006;22(2):405-415.

24. Edwards BJ, Langman $\mathrm{CB}$, Bunta $\mathrm{AD}$, et al. Secondary contributors to bone loss in osteoporosis related hip fractures. Osteoporos Int. 2008;19(7):991-999.

25. Kaiser MF, Heider U, Mieth M, et al. The proteasome inhibitor bortezomib stimulates osteoblastic differentiation of human osteoblast precursors via upregulation of vitamin D receptor signalling. Eur $J$ Haematol. 2003;90(4):263-272. 